\title{
Responses of Barley Cultivars and Lines to Isolates of Pyrenophora teres
}

\author{
A. Douiyssi, Plant Breeder, INRA Settat, Morocco; D. C. Rasmusson, Plant Breeder, Department of Agronomy \\ and Plant Genetics, University of Minnesota; and A. P. Roelfs, Cereal Rust Laboratory, USDA-ARS and the \\ Department of Plant Pathology, University of Minnesota, St. Paul 55108
}

\begin{abstract}
Douiyssi, A., Rasmusson, D. C., and Roelfs, A. P. 1998. Responses of barley cultivars and lines to isolates of Pyrenophora teres. Plant Dis. 82:316-321.

Net blotch, caused by Pyrenophora teres, is among the most damaging foliar diseases of barley worldwide. A knowledge of the reaction of local cultivars, putative resistant lines, and variability in the net blotch pathogen is necessary to develop a successful resistance breeding program. Disease responses of 38 barley lines to $15 P$. teres isolates were studied at the seedling and adult plant stages in the glasshouse, and field responses to net blotch were evaluated at three Moroccan locations. No tested barley was resistant to all isolates, and resistance was apparently of the specific type. Pathogenic variability was great, as none of the 15 isolates were identical. For each isolate tested, a specific high level of resistance was found in one or more host lines. Seedling and adults plants often differed in response to the same isolate. Adult plant resistance was commonly observed in response to isolate $\mathrm{I}-1$, and seedling resistance was more common to isolate I-14. Adult plant resistance of nine lines was undetected in seedling evaluations using isolate I-1. The seedling glasshouse and field responses of the barley lines varied considerably, limiting the value of seedling testing for resistance. Field reactions of resistant and moderately resistant were consistent across the three locations for the lines Heartland, Minn 7, CI 2333, and CI 2549. The variability observed in P. teres and failure to find lines with resistance to all isolates suggests that breeding for resistance should emphasize pyramiding of resistance genes.
\end{abstract}

The prevalence of net blotch in barley, caused by Pyrenophora teres Drechs., conidial state Drechslera teres (Sacc.) Shoemaker, has increased in recent years, and net blotch has become one of the most important foliar diseases in the Mediterranean countries and eastern Canada. Host resistance to this disease has been repeatedly reported. The USDA Spring Barley Collection was examined under field conditions in California (14), in Canada (2), and in Egypt (5) for sources of resistance to $P$. teres. The reaction of barley lines to isolates of $P$. teres is commonly studied in seedling plants at the two- to three-leaf stage. The seedling reaction to $P$. teres generally agrees with the adult plant reaction in the field (2); however, host reaction may vary with plant age (13). The incidence of net blotch is generally higher in older plants (16), but resistance increased with increasing plant age in certain Manchurian cultivars (10). Enhanced resistance

Corresponding author: D. C. Rasmusson E-mail: rasmu002@maroon.tc.umn.edu

Paper No. 22,234, Scientific Journal Series, Minnesota Agricultural Experiment Station.

Accepted for publication 3 December 1997.

Publication no. D-1998-0108-01R

This article is in the public domain and not copyrightable. It may be freely reprinted with customary crediting of the source. The American Phytopathological Society, 1998. in older plants was common to biotypes of $P$. teres producing net lesions, while greater susceptibility was found in response to those that produce spot lesions (20).

Variation in pathogenicity in $P$. teres was first emphasized by Pon (12). Differences in reaction to isolates from different geographical areas are well documented $(6,10-$ 12,15). Recently, 13 pathotypes of $P$. teres were identified from 91 Californian isolates on 22 differential barley lines (17). In Algeria, Egypt, Morocco, Tunisia, and Cyprus, 33 isolates formed four major groups, and none of the barley cultivars examined were highly resistant to all isolates (7).

Variability in response of cultivars to isolates may arise from differences in environmental conditions. High postinoculation temperature $\left(36^{\circ} \mathrm{C}\right)$ resulted in breakdown of resistance in two Ethiopian and four Manchurian cultivars to an isolate of $P$. teres (10). In contrast, high preinoculation temperature or high light intensity (430 $\mathrm{lm} / \mathrm{m}^{2}$ ) during a 48-h high-humidity incubation period enhanced resistance of these cultivars. Additionally, interactions occurred between isolates and duration of high humidity after inoculation. The effect of these factors on the successful selection of resistant lines has not been carefully considered. The differences in plant responses at seedling and adult plant growth stages reported in the literature (13) make designing an effective breeding strategy a challenge.
To implement a successful breeding strategy for disease resistance requires information on the reaction of local cultivars and putative resistant lines, and an understanding of the variability in the pathogen population and the degree of specificity in host-pathogen relationships. This study (i) characterized the response of 38 barley lines to Moroccan isolates of $P$. teres, (ii) determined the variability in pathogenicity of isolates of $P$. teres, (iii) determined the effect of host growth stage on resistance to $P$. teres, and (iv) assessed the potential for screening barley to $P$. teres in the glasshouse and field.

\section{MATERIALS AND METHODS}

Thirty-eight barley lines representing a wide range of reactions to net blotch and differing in origin were selected for study. The germ plasm used was divided into Moroccan cultivars, putative resistance sources, and malting types (Atlas and Moore are feed types). Their reported disease reactions and places of origin are given in Table 1.

Both the net and spot forms of $P$. teres occur in Morocco. Only barley leaves with characteristic net blotch symptoms of the net form were collected from several barley fields throughout Morocco during the 1992-93 season (Table 2). Most collections were made from the southern semiarid region that is the largest barley-growing area in Morocco, and from the experimental stations of the National Institute of Agronomic Research in Morocco (I.N.R.A.) where barley breeding is done. The isolates were collected in April, when the barley growth stage ranged from heading to maturity. The isolate I-15 from Tunisia was provided by M. Harrabi (National Institute of Agronomy, Tunisia).

Sections $(5 \times 5 \mathrm{~mm})$ were cut from leaves with characteristic net blotch lesions, surface sterilized in $50 \%$ ethanol for $15 \mathrm{~s}$ and $2 \%$ sodium hypochlorite for $30 \mathrm{~s}$, rinsed in sterile distilled water (21), and dried on sterilized filter paper. They were then placed on $20 \%$ water agar and incubated at $20^{\circ} \mathrm{C} \pm 1{ }^{\circ} \mathrm{C}$ with a 12 -h photoperiod to promote sporulation, which usually occurred after 3 to 5 days. A sterilized needle was used to transfer a single conidium of $P$. teres to a $17.7 \% \mathrm{~V} 8$ juice agar (V8 juice, $177 \mathrm{ml}$; agar, $20 \mathrm{~g}$; $\mathrm{CaCO}_{3}, 3 \mathrm{~g}$; distilled water $823 \mathrm{ml}$ ) in a petri dish. The dishes were incubated at $20^{\circ} \mathrm{C} \pm 1{ }^{\circ} \mathrm{C}$ with a 12-h photoperiod for 2 weeks to permit fungal growth and sporulation. To increase 
inoculum, the monoconidial culture on the V8 petri dish was cut into $5 \times 5 \mathrm{~mm}$ pieces with a sterilized needle, aseptically transferred to fresh V8 petri dishes, and incubated as above. After 17 days, conidia were harvested by adding about $2 \mathrm{ml}$ of sterile distilled water to the petri dish and scraping the culture with a glass rod. A surfactant, Tween 20, was added at the rate of 1 drop per $500 \mathrm{ml}$ of inoculum. The suspension was homogenized in a mixer for $30 \mathrm{~s}$ to allow mycelium fragmentation and conidia dispersion. At inoculation, the concentration of the inoculum suspension $(500 \mathrm{ml})$ was adjusted using a hemacytometer to 40 to $50 \times 10^{3}$ conidia per $\mathrm{ml}$. Preliminary tests showed that these concentrations assured good infection. In the case of poorly sporulating isolates, the concentration of mycelium was increased to 15 to $20 \times 10^{4}$ per $\mathrm{ml}$.

For seedling tests, the 38 host lines were planted in a randomized complete block design with three replicates, except for a single test with isolate I-11. None of the tests were repeated. Temperature in the glasshouse was relatively similar throughout the tests. For each host line, 8 to 10 seeds were sown in a 10 -cm-diameter plastic pot. The seedlings were inoculated when 17 days old at about the two- to three-leaf stage. Inoculum was applied with an atomizer until the plants were uniformly wet. Inoculated plants were incubated at high relative humidity for $48 \mathrm{~h}$. Subsequently, the plants were grown in the glasshouse at 20 to $25^{\circ} \mathrm{C}$. Response of barley seedlings to $P$. teres was evaluated as infection rating (IR) 10 days after inoculation, based on the central portions of the second and third leaves, according to a numerical scale of 1 (resistant) to 10 (susceptible) (19). An average infection rating for the 8 to 10 plants per pot was recorded.

To study advanced growth stages in the glasshouse, eight seeds of each barley line were sown in a 15 -cm-diameter plastic pot. Three replicates with one pot per replicate were tested. Inoculum for each isolate was prepared from fresh monoconidial source material that was increased on Moore bar-

Table 1. Barley lines and their reported reactions to Pyrenophora teres

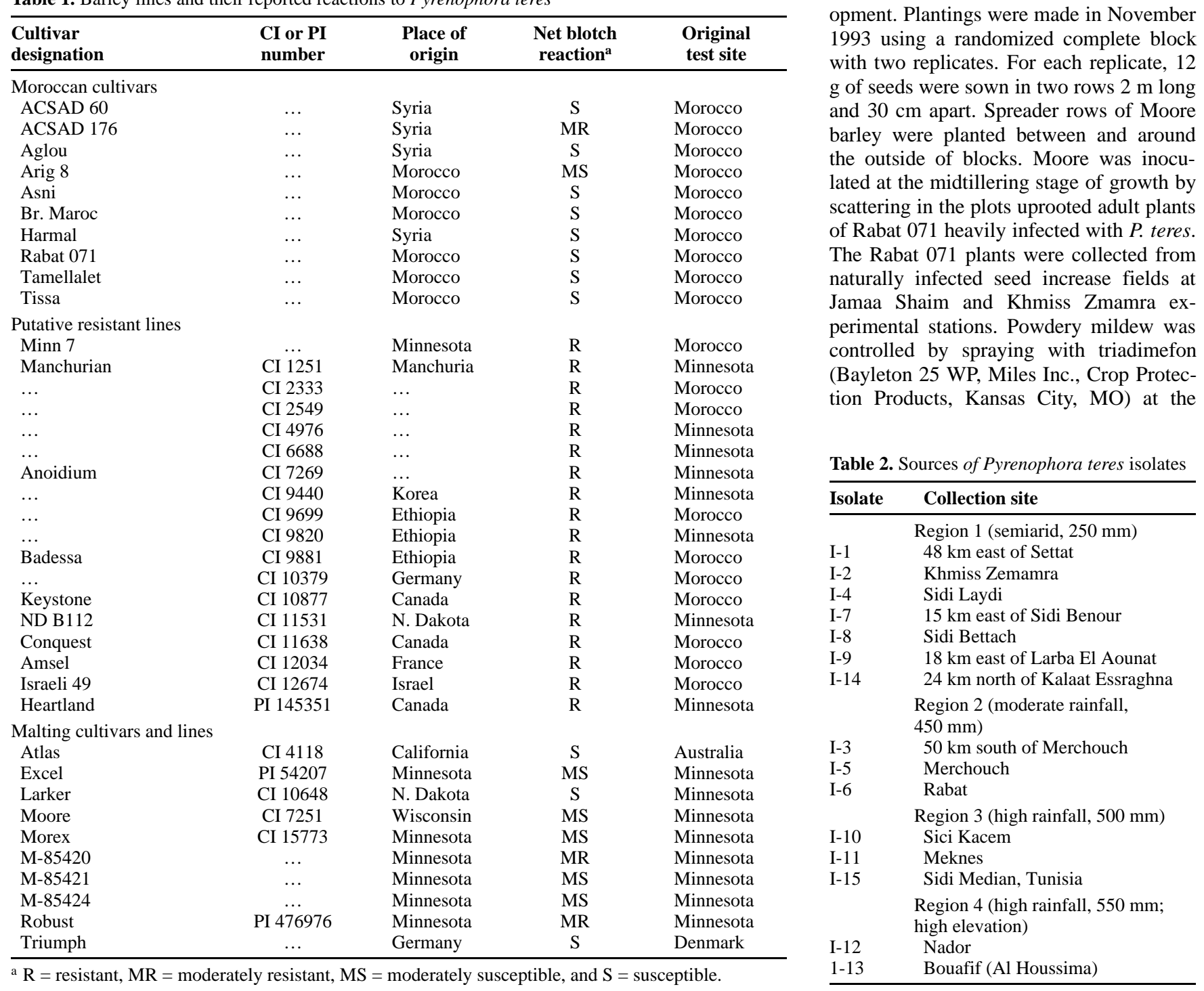

ley leaves in a glasshouse. Inoculum preparation and inoculation procedures were the same as described for the seedling test. Following the incubation period, plants were kept in a glasshouse at 20 to $25^{\circ} \mathrm{C}$ with an 11-h photoperiod. Plants were inoculated with isolate $\mathrm{I}-1$ of $P$. teres at the seedling (12 to 13 ), tillering (23 to 31 ), and heading stages (55 to 65 ), corresponding, respectively, to 17,27 , and 40 days after planting, and with isolate I-14 at the seedling and heading stages, 12 and 40 days after planting. Growth stages were based on the Zadoks scale (23). The selected isolates were collected from region 1 , where most barley in Morocco is grown, and they were chosen because they sporulated well and differed in virulence in seedling tests. Rating was based on symptom development on the fourth and fifth leaves in the tillering stage, and on flag and penultimate leaves at the heading stage.

Field testing of the 38 barley lines was done at Sidi Laydi, Jamaa Shaim, and Merchouch experimental stations in Morocco. Sidi Laydi and Jamaa Shaim are located in the semiarid region, and Merchouch is located in a moderate rainfall area favorable for foliar disease development. Plantings were made in November with two replicates. For each replicate, 12 $\mathrm{g}$ of seeds were sown in two rows $2 \mathrm{~m}$ long of Moore the outside of blocks. Moore was inocuated at the midtillering stage of growth by of Rabat 071 heavily infected with $P$. teres. Jamaa Shaim and Khmiss Zmamra ex(Bayleton 25 WP, Miles Inc., Crop Protec-

Table 2. Sources of Pyrenophora teres isolates Isolate Collection site

I-2 Khmiss Zemamr

I-4 Sidi Layd

I-8 Sidi Bettach

I-9 $18 \mathrm{~km}$ east of Larba El Aounat

I-14 $24 \mathrm{~km}$ north of Kalaat Essraghna

Region 2 (moderate rainfall,

Merchouch

Region 3 (high rainfall, $500 \mathrm{~mm}$ )

Sidi Median, Tunisia

Region 4 (high rainfall, $550 \mathrm{~mm}$

Nado

Plant Disease / March 1998317 
midtillering stage. Previous tests had shown that this treatment did not affect net blotch development or host response. Reaction responses in the field were assessed at the heading stage based on a scale of 1 (resistant) to 10 (susceptible).

Barley lines were placed into four classes in both field and glasshouse experiments, resistant $(\mathrm{R})$ when the IR mean of the three replicates ranged from 1.0 to 3.0, moderately resistant (MR) from 3.1 to 5.0, moderately susceptible (MS) from 5.1 to 7.0 , and susceptible (S) 7.1 or more. R plants had small lesions with no chlorosis; MR plants had larger lesions with some chlorosis; MS plants had large lesions with chlorosis and some netting; and S plants had large lesions with netting, severe chlorosis, and necrosis that often caused leaf death.
To detect specificity in the host-pathogen relationship, an analysis of variance (ANOVA) was used (22). The ANOVA was first calculated on infection ratings of barley lines caused by each isolate, and then infection-rating data were pooled in a combined analysis over all 14 pathogen isolates.

\section{RESULTS}

Seedling response of the 38 lines to the $15 P$. teres isolates was variable, ranging from 1 to 10 (Table 3), but there was a predominance of MR and MS ratings. Disease development progressed rapidly, and symptoms appeared on susceptible cultivars within $48 \mathrm{~h}$ after inoculation.

Each host line tested, except Anoidium, was $\mathrm{R}$ or MR to at least one isolate, but no

Table 3. Range of seedling infection response ${ }^{\mathrm{a}}$ of barley lines to 15 monoconidial isolates of Pyrenophora teres

\begin{tabular}{|c|c|c|c|c|c|c|}
\hline \multirow[b]{2}{*}{ Line designation } & \multirow{2}{*}{$\begin{array}{l}\text { Line } \\
\text { mean }\end{array}$} & \multirow{2}{*}{$\begin{array}{l}\text { Range of infection } \\
\text { response }\end{array}$} & \multicolumn{4}{|c|}{ Regional mean } \\
\hline & & & 1 & 2 & 3 & 4 \\
\hline \multicolumn{7}{|l|}{ Moroccan cultivars } \\
\hline ACSAD 60 & 5.5 & $2.3-8.0$ & 6.0 & 5.8 & 4.6 & 5.1 \\
\hline ACSAD 176 & 6.3 & $3.3-9.0$ & 5.8 & 6.2 & 8.2 & 5.2 \\
\hline Aglou & 5.7 & $9.5-1.3$ & 6.0 & 5.8 & 5.3 & 5.2 \\
\hline Arig 8 & 6.0 & $2.7-8.3$ & 6.0 & 6.8 & 5.3 & 6.2 \\
\hline Asni & 4.0 & $1.0-7.0$ & 4.4 & 4.4 & 1.2 & 5.8 \\
\hline Br. Maroc & 5.7 & $4.0-9.0$ & 5.8 & 5.6 & 5.6 & 6.0 \\
\hline Harmal & 5.5 & $1.3-7.7$ & 5.4 & 6.4 & 3.2 & 6.7 \\
\hline Rabat 071 & 4.9 & $1.3-7.7$ & 4.5 & 4.9 & 5.0 & 6.3 \\
\hline Tamellalet & 5.0 & $2.0-9.0$ & 4.7 & 6.6 & 5.2 & 3.2 \\
\hline Tissa & 5.1 & $1.0-7.0$ & 5.3 & 6.4 & 2.8 & 5.7 \\
\hline Mean (Moroccan) & 5.4 & & 5.4 & 5.9 & 4.6 & 5.5 \\
\hline \multicolumn{7}{|l|}{ Putative resistant lines } \\
\hline Minn 7 & 7.1 & $4.0-9.3$ & 6.8 & 7.7 & 6.3 & 8.3 \\
\hline Manchurian & 5.5 & $1.0-8.7$ & 6.1 & 6.4 & 3.4 & 5.0 \\
\hline CI 2333 & 4.4 & $1.0-8.0$ & 4.2 & 3.4 & 5.1 & 5.0 \\
\hline CI 2549 & 5.4 & $1.3-8.0$ & 5.9 & 4.9 & 4.4 & 6.2 \\
\hline CI 4976 & 4.7 & $1.7-8.0$ & 5.2 & 3.7 & 4.0 & 5.5 \\
\hline CI 6688 & 5.8 & $4.3-8.0$ & 5.5 & 6.1 & 5.9 & 5.8 \\
\hline Anoidium & 7.1 & $5.7-8.7$ & 6.6 & 7.3 & 7.9 & 7.0 \\
\hline CI 9440 & 4.7 & $1.3-6.7$ & 5.3 & 4.4 & 4.8 & 2.8 \\
\hline CI 9699 & 5.2 & $3.0-8.0$ & 5.9 & 4.7 & 3.9 & 5.3 \\
\hline CI 9820 & 4.2 & $1.0-7.0$ & 5.0 & 5.3 & 1.6 & 3.7 \\
\hline Badessa & 5.7 & $2.7-7.0$ & 6.4 & 5.9 & 3.7 & 6.0 \\
\hline CI 10379 & 5.3 & $3.0-7.3$ & 6.0 & 4.7 & 3.8 & 6.5 \\
\hline Keystone & 7.1 & $1.3-10.0$ & 8.3 & 5.8 & 5.8 & 7.2 \\
\hline ND B112 & 4.5 & $1.0-7.5$ & 5.4 & 4.6 & 1.4 & 5.7 \\
\hline Conquest & 5.4 & $2.0-7.3$ & 5.7 & 6.0 & 3.7 & 5.8 \\
\hline Amsel & 6.3 & $1.7-9.0$ & 6.2 & 6.7 & 6.8 & 5.5 \\
\hline Israeli 49 & 6.1 & $1.7-9.0$ & 6.5 & 5.8 & 4.4 & 7.7 \\
\hline Heartland & 4.1 & $1.0-6.3$ & 5.2 & 4.9 & 1.4 & 2.8 \\
\hline Mean (resistant) & 5.5 & & 5.9 & 5.5 & 4.4 & 5.6 \\
\hline \multicolumn{7}{|c|}{ Malting cultivars and lines } \\
\hline Atlas & 6.8 & $2.7-9.3$ & 6.7 & 7.4 & 7.3 & 5.5 \\
\hline Excel & 5.4 & $1.7-7.7$ & 5.4 & 7.1 & 3.3 & 6.0 \\
\hline Larker & 6.1 & $1.5-8.0$ & 6.7 & 6.8 & 3.4 & 7.2 \\
\hline Moore & 8.2 & $4.0-10.0$ & 8.3 & 8.4 & 8.7 & 6.8 \\
\hline Morex & 6.1 & $2.3-8.7$ & 6.8 & 8.0 & 2.6 & 6.3 \\
\hline M85-420 & 5.6 & $3.0-8.3$ & 5.8 & 6.7 & 4.6 & 5.2 \\
\hline M85-421 & 5.0 & $1.5-8.3$ & 5.4 & 6.8 & 2.2 & 5.0 \\
\hline M85-424 & 5.3 & $2.0-7.7$ & 5.7 & 6.8 & 2.9 & 5.2 \\
\hline Robust & 5.6 & $2.7-8.0$ & 5.6 & 6.3 & 4.4 & 6.3 \\
\hline Triumph & 5.0 & $1.0-7.7$ & 5.4 & 6.4 & 2.8 & 5.2 \\
\hline Mean (malting) & 5.9 & & 6.2 & 7.1 & 4.2 & 5.9 \\
\hline $\begin{array}{l}\text { Grand mean } \\
\text { (isolate) }\end{array}$ & 5.6 & & 5.8 & 6.1 & 4.4 & 5.7 \\
\hline $\operatorname{LSD}(5 \%)$ & 1.1 & & 1.1 & 1.2 & 1.1 & 1.1 \\
\hline
\end{tabular}

a On a scale of 1 to 10 , where resistant $=1$ to 3.0 , moderately resistant $=3.1$ to 5.0 , moderately susceptible $=5.1$ to 7.0 , and susceptible $=7.1$ to 10 . line was resistant to all isolates. The most resistant lines were Asni with a mean of 4.0 (range 1.0 to 7.0 ) and Heartland with a mean of 4.1 (range 1.0 to 6.3), while Moore with a mean of 8.2, Anoidium and Keystone and Minn 7 with 7.1 were the most susceptible.

While the most frequent response caused by each isolate was MR to MS, all $P$. teres isolates induced a susceptible reaction on at least two host lines. The seven isolates from region 1, except I-14, caused S or MS reactions on more than half of the lines in each of the three barley groups. Of these, isolate I-2 was the most pathogenic, causing an S or MS reaction on $100 \%$ of the barley lines in the putative resistant and malting groups and on $70 \%$ of the cultivars in the Moroccan group. Isolate I-8 caused an $\mathrm{S}$ or MS reaction on all members of the malting group. The average virulence of isolates from region 2 and 4 were similar to those from region 1 . Isolates from region 3 were less pathogenic with isolates I15 and I-10, causing S or MS reactions on only 26 and $40 \%$ of the 38 lines, respectively.

Specificity in host-pathogen relationships was indicated by significant isolate by cultivar interactions in the analysis of variance. Significant effects for pathogen isolate, host lines, and host by pathogen interaction for infection ratings were detected at the 0.01 probability level. An example of host by pathogen interaction are lines ND B112 and CI 12034 (putative resistant group), and isolates I-4 and I-10 from regions 1 and 4, respectively (Table 3 ). These lines exhibited both resistant and susceptible reactions depending on the isolate. No identical isolates were detected, suggesting that there are likely many more pathogenic races in Morocco than found in this study.

The 38 barley lines tested showed more resistance at the tillering and heading stages than at the seedling stage when inoculated with isolate I-1 (Table 4). This was true for each of the three barley groups. Among the Moroccan cultivars, there were $0 \% \mathrm{R}$ lines at the seedling, $30 \%$ at tillering, and $40 \%$ at the heading stage. However, not all lines behaved this way, and a change from moderately resistant to susceptible occurred with Harmal, and lesser changes toward more resistance occurred between seedling and heading in the lines ACSAD 176, Minn 7, CI 1251, CI 2549, CI 12674, and Atlas. While there was some divergence, most of the lines had ratings at the tillering stage intermediate to those found at the seedling and heading stages (Table 4).

However, with isolate I-14, the opposite was true. The 38 lines were more resistant at the seedling stage than at the heading stage (Table 4). A decrease in the number of lines with $\mathrm{R}$ or MR reaction occurred with increasing age in each of the barley groups. For example, in the Moroccan 
group, $50 \%$ of the cultivars were $\mathrm{R}$ at the seedling stage, while none were so at heading stage. While the majority of reaction changes to isolate I-14 were changes within a class, there were four changes to a greater susceptibility class as plants aged: CI 4976 and Atlas changed from resistant to susceptible and ACSAD 60 and Arig 8 changed from resistant to moderately susceptible.

Field experiments. Net blotch developed in field plots at all locations, and the mean response of 9.7 for Rabat 071, a highly susceptible cultivar, confirms the severity of the net blotch epidemic. Characteristic symptoms of the net form of $P$. teres occurred on the upper leaves of sus- ceptible lines. Host genotype, location, and the genotype by location interaction were significant $(P=0.01)$. Even so, field reactions of many R or MR lines and MS or $\mathrm{S}$ lines were consistent across the three locations, and no changes from resistant to susceptible classes occurred (Table 4).

The putative resistant lines were the most consistently resistant in the field test (Table 4). Lines with the highest mean level of resistance included CI 2333, CI 2549, and CI 9440, followed by CI 6688, Minn 7, Heartland, Amsel, and Anoidium. CI 10379 and Manchurian gave mostly MR responses across the three locations. Of the Moroccan cultivars, ACSAD 176 and Asni were consistently MR. Aglou and
Br. Maroc differed in response among locations. No consistent $\mathrm{R}$ or $\mathrm{MR}$ lines were found in the malting group, and all lines were MS or S at Sidi Laydi and Jamaa Shaim except M85-424 and Larker. At Merchouch, the Minnesota lines M85-420, M85-421, M85-424, Excel, and Robust had MR responses.

\section{DISCUSSION}

The mean reactions of the Moroccan, putative resistant, and malting barley groups in the seedling stage to various isolates were similar. Averaged over all isolates, reaction ranged from 4.0 to 6.3 for the Moroccan cultivars, 4.1 to 7.1 for the putative resistant lines, and 5.0 to 8.2 for

Table 4. Infection response ${ }^{\mathrm{a}}$ of barley lines at the seedling, tillering, and heading growth stages to monoconidial isolates of Pyrenophora teres in the glasshouse compared with the field response at three Moroccan locations

\begin{tabular}{|c|c|c|c|c|c|c|c|c|c|}
\hline \multirow{2}{*}{$\begin{array}{l}\text { Line } \\
\text { designation }\end{array}$} & \multicolumn{3}{|c|}{ Isolate I-1 } & \multicolumn{2}{|c|}{ Isolate I-14 } & \multicolumn{4}{|c|}{ Field reaction } \\
\hline & Seedling & Tillering & Heading & Seedling & Heading & Sidi Laydi & Jamaa Shaim & Merchouch & Line mean \\
\hline \multicolumn{10}{|c|}{ Moroccan cultivars } \\
\hline ACSAD 60 & 8.0 & 6.7 & 6.3 & 2.3 & 6.0 & 8.0 & 6.0 & 8.5 & 7.5 \\
\hline ACSAD 176 & 6.5 & 5.3 & 2.7 & 7.3 & 6.7 & 4.0 & 4.5 & 4.5 & 4.3 \\
\hline Aglou & 8.3 & 6.0 & 7.0 & 4.3 & 5.0 & 6.5 & 4.5 & 2.0 & 4.3 \\
\hline Arig 8 & 7.7 & 4.7 & 4.7 & 2.7 & 6.3 & 7.5 & 7.5 & 7.0 & 7.3 \\
\hline Asni & 4.0 & 2.3 & 2.7 & 2.0 & 5.0 & 5.0 & 4.5 & 3.5 & 4.3 \\
\hline Br. Maroc & 5.7 & 4.7 & 4.0 & 5.7 & 5.7 & 8.0 & 5.0 & 8.0 & 7.0 \\
\hline Harmal & 3.7 & 6.0 & 8.0 & 6.7 & 6.3 & 8.0 & 5.5 & 8.0 & 7.2 \\
\hline Rabat 071 & 6.7 & 3.0 & 2.0 & 1.3 & 3.7 & 9.0 & 10.0 & 10.0 & 9.7 \\
\hline Tamellalet & 8.7 & 5.3 & 3.7 & 3.7 & 6.3 & 6.0 & 5.0 & 4.0 & 5.0 \\
\hline Tissa & 5.0 & 2.7 & 2.7 & 2.7 & 5.0 & 6.5 & 5.5 & 4.0 & 5.3 \\
\hline $\begin{array}{l}\text { Mean } \\
\text { (Moroccan) }\end{array}$ & 6.4 & 4.7 & 4.4 & 3.9 & 5.6 & 6.9 & 5.8 & 6.0 & 6.2 \\
\hline \multicolumn{10}{|c|}{ Putative resistant lines } \\
\hline Minn 7 & 8.0 & 3.0 & 4.0 & 7.0 & 6.3 & 3.5 & 4.5 & 2.0 & 3.3 \\
\hline Manchurian & 6.3 & 2.3 & 2.7 & 5.7 & 6.0 & 4.5 & 5.0 & 5.0 & 4.8 \\
\hline CI 2333 & 1.7 & 2.3 & 4.3 & 5.7 & 5.7 & 2.0 & 4.5 & 2.5 & 3.0 \\
\hline CI 2549 & 7.0 & 4.7 & 3.0 & 4.7 & 6.3 & 3.5 & 3.0 & 2.5 & 3.0 \\
\hline CI 4976 & 4.0 & 2.7 & 4.3 & 2.0 & 7.0 & 8.0 & 9.0 & 9.5 & 8.8 \\
\hline CI 6688 & 6.0 & 2.0 & 4.7 & 5.5 & 6.0 & 4.0 & 3.0 & 2.5 & 3.2 \\
\hline Anoidium & 8.3 & 7.3 & 6.7 & 6.3 & 6.0 & 5.0 & 4.0 & 2.5 & 3.8 \\
\hline CI 9440 & 4.3 & 3.3 & 3.7 & 5.3 & 6.3 & 3.5 & 3.5 & 2.0 & 3.0 \\
\hline CI 9699 & 4.3 & 4.3 & 5.0 & 4.0 & 6.7 & 4.0 & 4.5 & 5.5 & 4.7 \\
\hline CI 9820 & 5.3 & 2.3 & 2.7 & 4.3 & 2.7 & 7.5 & 5.5 & 6.0 & 6.3 \\
\hline Badessa & 6.7 & 4.3 & 4.0 & 4.3 & 5.7 & 7.5 & 5.5 & 6.0 & 6.3 \\
\hline CI 10379 & 5.3 & 3.7 & 5.3 & 5.0 & 6.3 & 4.0 & 4.0 & 4.5 & 4.2 \\
\hline Keystone & 9.7 & 5.3 & 4.7 & 7.3 & 6.7 & 7.0 & 5.5 & 4.5 & 5.7 \\
\hline ND B112 & 4.7 & 3.7 & 2.3 & 3.3 & 5.3 & 5.5 & 7.5 & 5.5 & 6.2 \\
\hline Conquest & 5.7 & 2.7 & 2.7 & 2.7 & 5.0 & 3.0 & 6.5 & 3.5 & 4.3 \\
\hline Amsel & 7.3 & 5.0 & 6.3 & 7.0 & 6.3 & 4.5 & 3.0 & 4.0 & 3.8 \\
\hline Israeli 49 & 8.7 & 5.3 & 5.3 & 5.0 & 7.0 & 7.0 & 6.5 & 6.0 & 6.5 \\
\hline Heartland & 4.7 & 2.0 & 2.7 & 4.7 & 5.3 & 3.0 & 4.5 & 2.5 & 3.3 \\
\hline $\begin{array}{l}\text { Mean } \\
\quad \text { (resistant) }\end{array}$ & 6.0 & 3.7 & 4.1 & 5.0 & 5.9 & 4.9 & 5.0 & 4.3 & 4.7 \\
\hline \multicolumn{10}{|c|}{ Malting cultivars and lines } \\
\hline Atlas & 9.3 & 6.0 & 5.3 & 2.7 & 7.7 & 6.5 & 8.5 & 8.5 & 7.8 \\
\hline Excel & 4.3 & 2.5 & 2.5 & 5.0 & 5.7 & 6.0 & 6.5 & 5.0 & 5.8 \\
\hline Larker & 6.7 & 3.0 & 4.3 & 5.7 & 5.7 & 5.0 & 5.0 & 7.0 & 5.7 \\
\hline Moore & 9.7 & 7.0 & 7.0 & 9.7 & 7.3 & 8.0 & 8.0 & 9.0 & 8.3 \\
\hline Morex & 6.3 & 4.7 & 4.0 & 6.3 & 6.3 & 6.5 & 8.0 & 7.5 & 7.3 \\
\hline M85-420 & 6.0 & 2.7 & 3.3 & 4.3 & 5.7 & 6.0 & 6.0 & 4.0 & 5.3 \\
\hline M85-421 & 5.0 & 4.0 & 2.7 & 4.0 & 4.0 & 5.5 & 6.0 & 4.5 & 5.3 \\
\hline M85-424 & 4.0 & 2.7 & 3.3 & 4.3 & 6.0 & 6.5 & 5.0 & 4.0 & 5.2 \\
\hline Robust & 6.0 & 3.7 & 3.0 & 3.7 & 6.0 & 6.0 & 6.5 & 5.0 & 5.8 \\
\hline Triumph & 4.0 & 4.7 & 4.3 & 4.0 & 5.7 & 5.5 & 5.5 & 7.0 & 6.0 \\
\hline $\begin{array}{l}\text { Mean } \\
\text { (malting) }\end{array}$ & 6.1 & 4.1 & 4.0 & 5.0 & 6.0 & 6.2 & 6.5 & 6.2 & 6.0 \\
\hline $\begin{array}{l}\text { Grand mean } \\
\text { (isolate) }\end{array}$ & 6.2 & 4.1 & 4.2 & 4.6 & 5.8 & 6.0 & 5.8 & 5.5 & 5.7 \\
\hline $\operatorname{LSD}(5 \%)$ & 1.6 & 1.2 & 1.1 & 1.1 & 1.1 & 1.4 & 1.4 & 1.3 & 1.4 \\
\hline
\end{tabular}

${ }^{\mathrm{a}}$ On a scale of 1 to 10 , where resistant $=1$ to 3.0 , moderately resistant $=3.1$ to 5.0 , moderately susceptible $=5.1$ to 7.0 , and susceptible $=7.1$ to 10 . 
the malting cultivars. With the exception of ACSAD 176, the Moroccan cultivars are considered by barley breeders and pathologists to be susceptible to net blotch in the field; thus the R, MR, and MS reactions in the glasshouse were unexpected (Table 3 ). Especially surprising was the seedling resistance exhibited by Rabat 071 , a very susceptible cultivar in the field. Moroccan cultivars were introduced there from various countries in the Middle East and Europe (Table 1) and possibly possess different resistance genes.

The low frequency of seedling resistance in the putative resistance group was unexpected. Judging from these tests, the pathogen population and the general level of virulence in Moroccan isolates of $P$. teres may differ from other parts of the world, where many of these lines were reported to be resistant. While CI 4976 was $\mathrm{R}$ or MR to the isolates from region 2; CI 9699, CI 9820, Badessa, ND B112, and Heartland were $\mathrm{R}$ to the isolates in region 3; and CI 9440 and Heartland were R or $\mathrm{MR}$ to the isolates in region 4; none of the lines was $\mathrm{R}$ or MR to the isolates from region 1. Anoidium was $\mathrm{S}$ or MS to all the isolates tested.

Over two-thirds of the individual $P$. teres isolates from the four regions caused an intermediate reaction in the Moroccan cultivars (MR or MS). In region 1, which comprises about $70 \%$ of the Moroccan barley area, Tamellalet was R or MR to six of the seven isolates from the region, and Asni and Rabat 071 were R or MR to five of seven isolates. The cultivars Arig 8, Br. Moroc, ACSAD 60, ACSAD 176, and Harmal were $S$ or MS to most isolates from region 1 . These cultivars have been grown in region 1 for at least 8 years, and it is possible that the region 1 isolates have overcome their genes for resistance. Among the malting lines, more than $60 \%$ were $\mathrm{S}$ or MS to all isolates, except for isolates from region 3, where resistant reactions were common. Moore barley was moderately susceptible to susceptible to the largest number of isolates, 14, followed by Larker and Morex at 13 and Atlas at 12.

In region 3, bread and durum wheat are the predominant cereals and little barley is grown, which may explain the low virulence of isolates from this region. In contrast, the high level of virulence in regions 1,2 , and 4 , where barley is widely grown, may be explained by selection favoring virulent isolates. The most virulent isolates were from region 2 .

It is difficult to compare these findings with those of other authors because different barley lines, methods, and assessment protocols were used. However, the general pattern of variation for virulence in the net blotch pathogen in Morocco, as illustrated in Table 3, is similar to that reported elsewhere $(1,8,17,18)$.

Specific rather than generalized resistance and virulence mechanisms exist, as shown by the significant cultivar by isolate interaction. Resistance was effective against some isolates and ineffective against others; and no nonspecific resistance (similar level to all or nearly all isolates) was observed. The high degree of specificity in the population of $P$. teres may indicate that rapid adaptation to a particular host cultivar and loss of effective resistance may be the rule rather than the exception. Thus, designing effective breeding strategies is a challenge.

Changes in response with growth stage confirm that reaction to $P$. teres varies depending on growth stage $(9,12,16,20)$. Such changes in disease reactions were pathogen-isolate specific, as reported previously (20). For example, for isolate I-1, all lines except Harmal with an R or MR in the seedling stage also were $\mathrm{R}$ or MR at the adult stage. By contrast, of 24 lines with an $\mathrm{R}$ or MR to isolate I-14 in the seedling stage only, six were $\mathrm{R}$ or MR at the adult stage. With isolate $\mathrm{I}-1$, the adult plant resistance $(\mathrm{R}$ or MR) of nine lines would have been undetected in seedling evaluations. This inconsistency in disease reaction between seedling and heading stages means that seedling reaction is not predictive of adult plant response and vice versa.

In the field, putative resistant lines were superior to either the Moroccan cultivar group or the malting type group. It appears that several of the putative resistant sources, including Heartland and Minn 7, could be used to improve the resistance level of Moroccan cultivars. However, some of the putative resistant sources did not provide resistance in the field in Morocco. CI 4976 and CI 9820, reported to be resistant in seedling greenhouse and field testing in Canada and Minnesota $(2,8,18)$, were susceptible in the field in Morocco.

The mean response of seedling plants in the glasshouse and the mean response of adult plants in the field varied considerably, and changes of more than two units occurred for 8 of the 38 lines. The lines that differed the most between glasshouse and field were Rabat 071 and CI 4976; both were susceptible in the field and moderately resistant or moderately susceptible in the glasshouse. By contrast, Minn 7 and Anoidium were moderately resistant in the field and susceptible in the glasshouse. Factors other than resistance and pathogen virulence that can affect disease response are host growth stage, temperature, and light variations. The importance of temperature in infection response was stressed by Khan and Boyd (10). They showed that high preinoculation temperature enhanced resistance and high postinoculation temperature reduced resistance. In these experiments, temperature was monitored in glasshouses but not in the field. Inconsistency between glasshouse and field results was reported earlier $(3,4)$.

Likewise, there was poor agreement between mean response of the adult plants (heading stage) in the glasshouse and in the field. Changes of more than two units occurred for 17 lines with isolate I-1 and for 11 of the 38 lines with isolate I-14. The lines that varied the most in response were Rabat 071 and CI 9820, which were susceptible in the field and resistant in the glasshouse, and Amsel, which was resistant in the field and moderately susceptible in the glasshouse.

Finding differences in pathogenicity among isolates, significant genotype by isolate interaction, and lack of agreement between disease score of seedling plants and adult plants in the glasshouse, and adult plants in the field, point to substantial limitations in seedling screening of untested germ plasm within the context of breeding for resistance. Clearly, selection programs that utilize single isolates of $P$. teres in the glasshouse may result in lines that are susceptible in the field.

\section{LITERATURE CITED}

1. Afanasenko, O. S., and Lavitin, M. M. 1979. The population structure of the pathogen of net blotch of barley as regards its virulence. I. Identification of races. Mikol. Fitopatol. 13:230-234.

2. Buchannon, K. W., and McDonald, W. C. 1965. Source of resistance in barley to $P y$ renophora teres. Can. J. Plant Sci. 45:189193.

3. Clifford, B. C., and Jones, E. R. L. 1983. Net blotch of barley. Pages 77-81 in: U.K. Cereal Pathogen Virulence Survey 1982 Annu. Rep.

4. Deadman, M. L., and Cooke, B. M. 1986. A comparison of detached leaf, greenhouse and field experiments for screening barley cultivars to Drechslera teres. Isr. J. Agric. Res. 25:63-70.

5. Dessouki, S. M., Mansour, A. A., and Khalifa, M. I. 1965. Genetic sources of resistance to net blotch of barley. Agric. Res. Cairo 43:4752.

6. Gray, G. G. 1966. Genetic systems on the net blotch disease complex of barley. Ph.D. thesis. North Dakota State University, Fargo.

7. Harrabi, M., and Kamel, A. 1990. Virulence spectrum to barley in some isolates of $\mathrm{Py}$ renophora teres from the Mediterranean region. Plant Dis. 74:230-232.

8. Keeling, B. L., and Banttari, E. E. 1975. Factors associated with the resistance of barley to Helminthosporium teres. Phytopathology 65:464-467.

9. Khan, T. N., and Boyd, W. J. R. 1969. Physiologic specialization in Drechslera teres. Aust. J. Biol. Sci. 22:1229-1235.

10. Khan, T. N., and Boyd, W. J. R. 1969. Environmentally induced variability in the host reaction of barley to net blotch. Aust. J. Biol. Sci. 22:1237-1244.

11. McDonald, W. C., and Buchannon, K. W. 1962. The inheritance of variability in $P y$ renophora teres. Barley Newsl. 6:40.

12. Pon, D. S. 1949. Physiologic specialization and variation in Helminthosporium teres. (Abstr.) Phytopathology 38:18.

13. Populer, C. 1978. Changes in host susceptibility with time. Pages 239-262 in: Plant Disease - An Advanced Treatise. Vol. 2. J. G. Horsfall and E. B. Cowling, eds. Academic Press, New York.

14. Schaller, C. W., and Wiebe, A. E. 1952. Source of resistance to net blotch of barley. Agron. J. 44:334-336.

15. Shipton, W. A., Khan, T. N., and Boyd, W. J. R. 1973. Net blotch of barley. Rev. Plant Pa- 
thol. 52:269-351.

16. Singh, S. 1963. Effect of age of host and age of pathogen on the incidence of net blotch in barley (Helminthosporium teres Sacc.). Indian Phytopathol. 16:133-137.

17. Steffenson, B. J., and Webster, R. K. 1992. Pathotype diversity of Pyrenophora teres $\mathrm{f}$. teres on barley. Phytopathology 82:170-177.

18. Suganda, T., and Wilcoxson, R. D. 1993. Pathogenicity of Pyrenophora teres f. teres and $P$. teres f. maculata, resistance of barley, and biological and environmental effects on selection for resistance to $P$. teres $\mathrm{f}$. teres. Int. J. Trop. Plant Dis. 11:147-160.

19. Tekauz, A. 1985. A numerical scale to classify reactions of barley to Pyrenophora teres. Can. J. Plant Pathol. 7:181-183.

20. Tekauz, A. 1986. Effect of plant age and leaf position on the reaction of barley to Pyrenophora teres. Can. J. Plant Pathol. 8:380-386.
21. Tekauz, A. 1990. Characterization and distribution of pathogenic variation in Pyreno phora teres f. teres and P. teres f. maculata from western Canada. Can. J. Plant Pathol 12:141-148.

22. Vanderplank, J. E. 1968. Disease Resistance in Plants. Academic Press, New York.

23. Zadoks, J. C., Chang, T. T., and Konzak, C. F. 1974. A decimal code for the growth stages of cereals. Weed Res. 14:415-421. 